\title{
CRIMSONpublishers
}

\author{
http://www.crimsonpublishers.com
}

Clinical Image

Tech Neurosurg Neurol

ISSN 2637-7748

\section{Elsberg Syndrome}

\section{Ghassan George Haddad*}

Le Boulevard Bldg $6^{\text {th }}$ floor, Lebanon

*Corresponding author: Ghassan George Haddad, Le Boulevard Bldg 6th floor, Jdeidet El Metn, Lebanon

Submission: July 10, 2017; Published: November 13, 2017

\section{Introduction}

Elsberg syndrome (ES) is an infectious syndrome consisting of acute bilateral lumbosacral radiculitis, often accompanied by myelitis confined to the lower spinal cord, and is frequently a manifestation of reactivation, or occasionally, primary herpes simplex virus 2 infection [1].

The onset of ES is consistently acute and symptoms includes: Urinary retention, urinary incontinence, bowel incontinence, saddle anesthesia, exaggerated/pathologic lower limb tendon reflexes or absent lower limb tendon reflexes, Loss of limb sensation and Leg weakness [2].
Clinical picture, MRI, EMG and CSF studies confirm the diagnosis.

EMG shows evidence of radiculopathies.

MRI of the Spinal cord lesions (Figure 1) shows multiple, discontinuous, and centrally or ventrally positioned lesions generally sparing the distal conus. Nerve root enhancement is prominent and smooth rather than nodular [3] shows Lymphocytic CSF pleocytosis CSF proteins were consistently elevated, and oligoclonal bands are rarely detected. CSF PCR is positive for VZV and $43 \%$ of cases have viral isolation studies positive for herpes.

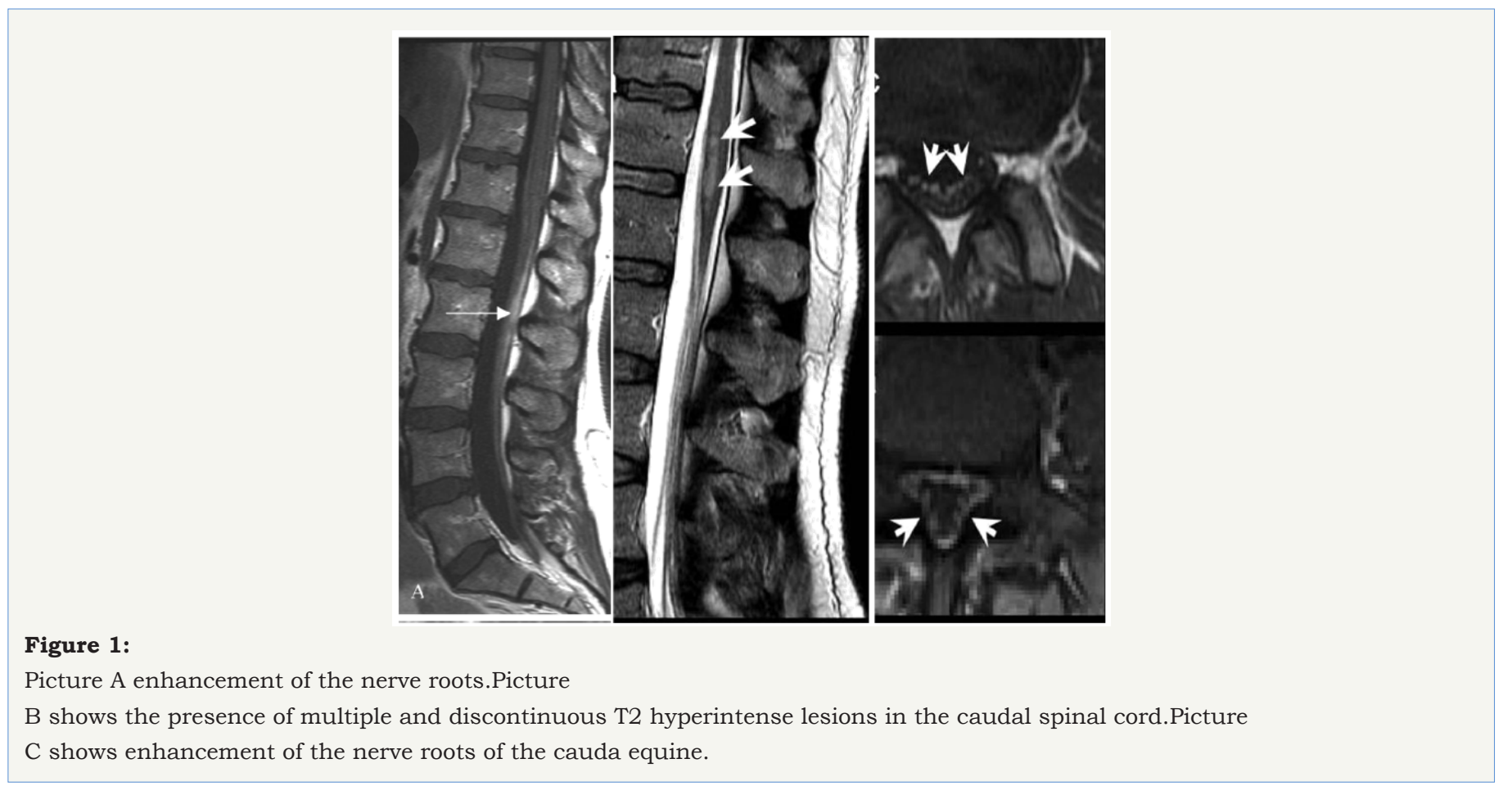

\section{Differential diagnosis includes}

I. Lymphoma, Spinal neoplasms, Vascular disorders (dural arteriovenous fistula).

II. Guillain-Barre'syndrome, chronic inflammatory demyelinating, polyneuropathy, MS, NMO or clinically isolated demyelinating syndrome.
III. Myelitis secondary to systemic autoimmune diseases (sarcoidosis, SLE, Sjögren, Behçet, and systemic sclerosis).

\section{Infectious myelitis}
a. viral (not herpes), bacterial, fungal, lyme or parasitic.
b. Infectious brain infection (encephalitis or meningitis)
c. Paraneoplastic myelitis 


\section{d. Motor neuron disease}

e. Radiation myelopathy

f. Metabolic myelopathy (vitamins B12, D, E, and copper deficiencies)

\section{Treatment}

Acyclovir is the treatment of choice and most patients recover with sequelae.

\section{References}

1. Eberhardt O, Kuker W, Dichgans J, Weller M (2004) HSV-2 sacral radiculitis (Elsberg syndrome). Neurology 63(4): 758-759.

2. Caplan LR, Kleeman FJ, Berg S (1977) Urinary retention probably secondary to herpes genitalis. N Engl J Med 297(17):920-921.

3. Smith JK, Lury K, Castillo M (2006) Imaging of spinal and spinal cord tumors. Semin Roentgenol 41:274-293. 